\title{
A Brief Overview of Medical Management Options in Peripheral Arterial Disease
}

International Journal of Cardiology and Cardiovascular Disorder

Mini Review Article

\author{
Usman Sarwar MD" ${ }^{1 *}$, Ali Hussain $\mathrm{MD}^{2}$, Nikky Bardia MD', Muhammad Nadeem $\mathrm{MD}^{3}$ and Hassan Tahir MD \\ ${ }^{1}$ Department of Cardiology, University of South Alabama, \\ Mobile, AL, USA \\ ${ }^{2}$ Sentara Albemarle Medical Center, NC, USA \\ ${ }^{3}$ Saint Michael's Medical Center, NJ,USA \\ ${ }^{4}$ Department of Cardiology, Heart Lung Vascular Institute, \\ University of Tennessee Medical Center, Knoxville, TN, USA \\ *Correspondence author \\ Usman Sarwar MD \\ Department of Cardiology \\ University of South Alabama \\ Mobile \\ AL \\ USA \\ Submitted : 9 Sept 2021 ; Published : 23 Sept 2021

\begin{abstract}
Peripheral arterial disease (PAD) has significant mortality and morbidity along with poor quality of life yet not very well understood by the medical community, and it remains under diagnosed and less optimally treated medically. Optimized Medical treatment along with risk factor modification is the fundamental principle of PAD treatment. In this article, we reviewed the evidence-based medical management of PAD.
\end{abstract}

Keywords: Peripheral Arterial Disease; Transient Ischemic Attack; Dual Antiplatelet Therapy.

\section{Introduction}

Peripheral artery disease (PAD) is defined as the presence of stenosis or occlusion in aorta or arteries of limbs. The global burden of PAD is enormous, with more than 200 million people. This disease has significant disability and mortality. The incidence of morbidity and mortality has been increased tremendously in last recent years. Besides cardiovascular diseases such as coronary disease or stroke, smoking is the most important risk factor for PAD. Other risk factors include hypertension, hyperlipidemia, and advanced age. PAD is a marker of advanced arteriosclerosis overall, as shown by studies. In one big study REACH registry, approximately $25 \%$ of patients with PAD had a MI, $30 \%$ had angina, and $15 \%$ had a history of TIA. Peripheral artery disease is also especially important to diagnose because studies have shown that abnormal ankle-brachial index (ABI) is linked to increased mortality risk [1-3].

Medical therapy for PAD can be divided into two big categories. One category involves cardiovascular risk reduction, and the other involves improvement in leg symptoms. A brief review of all therapies is mentioned below.

\section{Role of Antihyperlipidemic}

The American College of Cardiology (ACC) recommends consider PAD equal to myocardial infarction or stroke regarding target LDL control; therefore, statins are the cornerstone of PAD medical management and have Class I indication to use in guidelines $[5,6]$. The benefits of starting statin in PAD manifested very early on in the Heart Protection Study that showed the use of statin in PAD lead to a $24 \%$ relative risk reduction in events rate as compared to the control group [4]. REACH registry later also proved that the use of statin could decrease the incidence of critical limb ischemia, new limb revascularization, and amputation [2].

Regarding antihyperlipidemic therapy, the first-line drug is a high-intensity statin. Even after using a high-intensity statin, if serum LDL levels are not less than $70 \mathrm{mg} / \mathrm{dL}$, there is a role of adding ezetimibe according to the IMPROVE-IT trial [7]. PCSK 9 inhibitors are also especially useful in PAD if LDL $>70 \mathrm{mg} / \mathrm{dl}$ after using high-intensity statin and ezetimibe, as demonstrated in the FOURIER study. In the FOURIER study, patients who had PAD and were treated with evolocumab showed a $3.5 \%$ absolute risk reduction in the primary endpoint of $\mathrm{CV}$ death, MI, or stroke. FOURIER study also showed a decrease in acute limb events (major amputation, acute limb ischemia or urgent revascularization) in patients who were on evolocumab as compared to placebo [8].

\section{Role of antiplatelet}

Antiplatelets also have a key role in the management of peripheral rial disease. Regarding aspirin, some studies initially did not show much benefit, but later studies showed benefits in terms of vascular death, stroke, and MI $[9,10]$.

In patients with atherosclerotic cerebrovascular disease (ASCVD), Clopidogrel was compared against aspirin in CAPRIE trial. This trial favored clopidogrel over aspirin in patients with peripheral artery disease; currently, guidelines had no preference of using clopidogrel in peripheral artery 
disease patients over aspirin as a single antiplatelet agent [6]. With the advent of new P2Y12 inhibitors, ticagrelor was studied as compared to clopidogrel in the EUCLID trial. In this trial, ticagrelor was not found to be superior as compared to clopidogrel in terms of reduction of major cardiovascular events [12].

\section{Role of dual antiplatelet therapy}

The role dual antiplatelet therapy (DAPT) was studied in a patient population that also has PAD in the CHARISMA (Clopidogrel for High Atherothrombotic Risk and Ischemic Stabilization, Management, and Avoidance) trial. The primary outcome of the CHARISMA trial measured in terms of death, stroke, bleeding, and MI. This trial did not show any significant difference between DAPT vs. single antiplatelet therapy in the overall included population; currently, there is no convincing evidence of using dual antiplatelet therapy in a patient with PAD, and current guidelines have class IIb indication for using DAPT in PAD [13].

\section{Role of anticoagulation}

The role of anticoagulation in PAD was studied because pathological analysis of amputated limbs showed evidence of thrombosis [14]. Initially trial used warfarin. The result of these trials was not very promising, most likely due to poor compliance and a high discontinuation rate, and increased risk of fatal bleeding [15-17]. Later with the introduction of novel anticoagulation agents' further studies were done, and the COMPASS trial is one of the most important studies among them. In COMPASS trial patients were randomized into three categories. One group was treated with aspirin alone, the other group was treated with $5 \mathrm{mg}$ rivaroxaban twice daily, and the third group received aspirin (100 mg) plus $2.5 \mathrm{mg}$ rivaroxaban twice daily, cardiovascular death, stroke, or MI selected as primary outcomes. Rivaroxaban plus aspirin group showed $24 \%$ relative risk reduction as compared to aspirin group alone after following for 23 months. The sub-analysis also showed that a combination of rivaroxaban plus aspirin was also beneficial in decreasing major acute adverse limb events (acute limb ischemia or chronic limb ischemia requiring revascularization) [28]. From a bleeding perspective, the trial, as expected, did show there is more risk of non-fatal bleeding in rivaroxaban plus aspirin growth as compared to aspirin alone, no significant difference exists between two groups with regards to fatal bleeding [18]. Another trial, VOYAGER PAD, which was recently published in 2020 , showed a beneficial effect of combining aspirin plus low-dose rivaroxaban $(2.5 \mathrm{mg}$ twice daily) versus aspirin alone. The primary endpoint in the VOYAGER trial was acute limb ischemia, major amputation, MI, ischemic, or CV death. Rivaroxaban group showed a $15 \%$ relative risk reduction in the primary endpoint [19].

\section{Role of vasodilator}

Peripheral artery disease claudication due to decreased blood flow; therefore, drugs that can vasodilate the peripheral arteries are potentially beneficial. Two drugs were initially tried cilostazol and pentoxifylline. Currently, only cilostazol is used for this purpose and carries class IA indication in patients experiencing claudication in guidelines [6]. Its work-up by inhibiting phosphodiesterase inhibitor three and improved quality of life by decreasing claudication. It is especially important that cilostazol should not be given to heart failure patients because it can exacerbate heart failure [20, 21].

Role of supervised exercise therapy

Supervised exercise therapy 3-5 supervised sessions per week with a duration of 30 to 60 minutes showed tremendous improvement in maximal walking distance, and it is supported by literature [22].

\section{Role of blood pressure control and smoking cessation}

Blood pressure control is also especially important and patients with peripheral artery disease. The current European guidelines recommend blood pressure control of less than $140 / 90 \mathrm{~mm}$ of $\mathrm{Hg}$, and ACC guidelines recommend treating blood pressure $>130 / 80 \mathrm{~mm}$ of $\mathrm{Hg}$. Regarding the choice of medication, ACE inhibitors are more preferred in guidelines with class II recommendations [6,24,25].

Among risk factor reduction, smoking cessation is crucially important because smoking increases the risk of PAD by 2-3 folds. Ideally, two methods, i.e., nicotine gum plus pharmacological approach, should be tried [26, 27].

\section{Conclusion}

In conclusion, peripheral artery disease, associated with significant mortality and morbidity along with a poor quality of life. All patients should have good hyperlipidemia control. Studies have shown the benefits of combining aspirin with low-dose rivaroxaban. Smoking cessation and participation in supervised exercise programs have long-term benefits $[11,23]$

\section{Conflicts of Interest}

None

Funding

None

Acknowledgment

None

\section{References}

1. Jones, WS, Patel, MR, Dai, D, Vemulapalli, S, Subherwal, S, Stafford, J, Peterson, ED (2013). High mortality risks after major lower extremity amputation in Medicare patients with peripheral artery disease. Am Heart $J$, 165(5), 809-15, 815.e1. doi: 10.1016/j.ahj.2012.12.00

2. Ohman, EM, Bhatt, DL, Steg, PG, Goto, S, Hirsch, AT, Liau, CS, Mas, JL, Richard, AJ, Röther, J, Wilson, PW; REACH Registry Investigators (2006). The Reduction of Atherothrombosis for Continued Health (REACH) registry: an international, prospective, observational investigation in subjects at risk for atherothrombotic events-study design. Am Heart J, 151(2), 786.e1-786.10. doi: 10.1016/j.ahj.2005.11.004 Crossref.

3. Fowkes, FG, Rudan, D, Rudan, I, Aboyans, V, Denenberg, JO, McDermott, MM, Norman, PE, Sampson, UK, Williams, LJ, Mensah, GA, et al (2013). Comparison 
of global estimates of prevalence and risk factors for peripheral artery disease in 2000 and 2010: a systematic review and analysis. Lancet, 382(9902), 1329-1340. doi: 10.1016/S0140-6736(13)61249-0 Crossref. PubMed.

4. Heart Protection Study Collaborative Group. MRC/BHF Heart Protection Study of cholesterol lowering with simvastatin in 20,536 high-risk individuals: A randomised placebo-controlled trial. Lancet. 2002 Jul 6, 360(9326), 7-22. doi:10.1016/S0140-6736(02)09327-3.

PMID: 12114036.

5. Grundy, SM, Stone, NJ, Bailey, AL, Beam, C, Birtcher, KK, Blumenthal, RS, Braun, LT, de Ferranti, S, FaiellaTommasino, J, Forman, DE, et al (2019). 2018 AHA/ ACC/AACVPR/AAPA/ABC/ACPM/ADA/AGS/APhA/ ASPC/NLA/PCNA guideline on the management of blood cholesterol: a report of the American College of Cardiology/American Heart Association task force on clinical practice guidelines. J Am Coll Cardiol, 73(24), e285-e350. doi: 10.1016/j.jacc.2018.11.003 Crossref. PubMed.

6. Gerhard-Herman, MD, Gornik, HL, Barrett, C, Barshes, NR, Corriere, MA, Drachman, DE, Fleisher, LA, Fowkes, FG, Hamburg, NM, Kinlay, S, et al (2017). 2016 AHA/ ACC guideline on the management of patients with lower extremity peripheral artery disease: executive summary: a report of the American College of Cardiology/ American Heart Association task force on clinical practice guidelines. Circulation, 135(12), e686-e725.

doi: 10.1161/CIR.0000000000000470 Crossref. PubMed.

7. Murphy, SA, Cannon, CP, Blazing, MA, Giugliano, RP, White, JA, Lokhnygina, Y, Reist, C, Im, K, Bohula, EA, Isaza, D, et al (2016). Reduction in total cardiovascular events with ezetimibe/simvastatin post-acute coronary syndrome: the IMPROVE-IT trial. J Am Coll Cardiol, 67(4), 353-361. doi: 10.1016/j.jacc.2015.10.077 Crossref. PubMed.

8. Bonaca MP, Nault P, Giugliano RP, Keech AC, Pineda AL, Kanevsky E, Kuder J, Murphy SA, Jukema JW, Lewis BS, Tokgozoglu L, Somaratne R, Sever PS, Pedersen TR, Sabatine MS (2018). Low-Density Lipoprotein Cholesterol Lowering with Evolocumab and Outcomes in Patients with Peripheral Artery Disease: Insights from the FOURIER Trial (Further Cardiovascular Outcomes Research with PCSK9 Inhibition in Subjects with Elevated Risk). Circulation, 137(4), 338-350.

doi: 10.1161/CIRCULATIONAHA.117.032235.

Epub 2017 Nov 13. PMID: 29133605. Fourier

9. Antithrombotic Trialists' Collaboration. Collaborative meta-analysis of randomised trials of antiplatelet therapy for prevention of death, myocardial infarction, and stroke in high risk patients. $B M J .2002 ; 324: 71-86$. doi: $10.1136 / \mathrm{bmj} .324 .7329 .71$

10. Sigvant B, Lundin F, Wahlberg E (2016). The risk of disease progression in PAD is higher than expected: A meta-analysis of mortality and disease progression in PAD. Eur J Vasc Endovasc Surg, 51(3), 395-403. doi: 10.1016/j.ejvs.2015.10.022

11. Gerhard-Herman MD, Gornik HL, Barrett C, Barshes
NR, Corriere MA, Drachman DE, Fleisher LA, Fowkes FG, Hamburg NM, Kinlay S, et al (2017). 2016 AHA/ ACC guideline on the management of patients with lower extremity peripheral artery disease: executive summary: a report of the American College of Cardiology/ American Heart Association task force on clinical practice guidelines. Circulation, 135(12), e686-e725.

doi: 10.1161/CIR.0000000000000470

12. Hiatt WR, Fowkes FG, Heizer G, Berger JS, Baumgartner I, Held P, Katona BG, Mahaffey KW, Norgren L, Jones WS, et al.; EUCLID Trial Steering Committee and Investigators (2017). Ticagrelor versus clopidogrel in symptomatic peripheral artery disease. $N$ Engl $J$ Med, 376(1), 32-40. doi: 10.1056/NEJMoa1611688

13. Bhatt DL, Fox KA, Hacke W, Berger PB, Black HR, Boden WE, Cacoub P, Cohen EA, Creager MA, Easton JD, et al.; CHARISMA Investigators (2006). Clopidogrel and aspirin versus aspirin alone for the prevention of atherothrombotic events. $N$ Engl J Med, 354(16), 17061717. doi: 10.1056/NEJMoa060989

14. Narula N, Dannenberg AJ, Olin JW, Bhatt DL, Johnson KW, Nadkarni G, Min J, Torii S, Poojary P, Anand SS, et al (2018). Pathology of peripheral artery disease in patients with critical limb ischemia. $J$ Am Coll Cardiol, 72(18), 2152-2163. doi: 10.1016/j.jacc.2018.08.002

15. Anand SS, Yusuf S, Pogue J, Weitz JI, Flather M (1998). Long-term oral anticoagulant therapy in patients with unstable angina or suspected non-Q-wave myocardial infarction: Organization to Assess Strategies for Ischemic Syndromes (OASIS) pilot study results. Circulation, 98(11), 1064-1070. doi: 10.1161/01.cir.98.11.1064

16. Hurlen M, Abdelnoor M, Smith P, Erikssen J, Arnesen $\mathrm{H}$ (2002). Warfarin, aspirin, or both after myocardial infarction. Engl J Med, 347(13), 969-974. doi: 10.1056/ NEJMoa020496

17. Anand S, Yusuf S, Xie C, Pogue J, Eikelboom J, Budaj A, Sussex B, Liu L, Guzman R, Cina C (2007). Warfarin Antiplatelet Vascular Evaluation Trial Investigators. Oral anticoagulant and antiplatelet therapy and PAD. $N$ Engl $J$ Med, 357, 217-227. doi: 10.1056/NEJMoa065959 CrossrefMedlineGoogle Scholar

18. Eikelboom JW, Connolly SJ, Bosch J, Dagenais GR, Hart RG, Shestakovska O, Diaz R, Alings M, Lonn EM, Anand SS, et al.; COMPASS Investigators (2017). Rivaroxaban with or without aspirin in stable cardiovascular disease. $N$ Engl J Med, 377(14), 1319-1330. doi: 10.1056/ NEJMoa1709118

19. Bonaca, Marc P., et al (2020). Rivaroxaban in Peripheral Artery Disease after Revascularization. New England Journal of Medicine, 382(21), May 2020, 1994-2004. doi: 10.1056/NEJMoa2000052

20. Robless P, Mikhailidis DP, Stansby GP (2008). Cilostazol for peripheral arterial disease. Cochrane Database Syst Rev, 23(1), CD003748.

21. Bedenis R, Stewart M, Cleanthis M, Robless P, Mikhailidis DP, Stansby G (2014). Cilostazol for intermittent claudication. Cochrane Database Syst Rev, CD003748.

22. Lane R, Harwood A, Watson L, Leng GC (2017). Exercise 
for intermittent claudication. Cochrane Database Syst Rev, 12, CD000990. doi: 10.1002/14651858.CD000990. pub4

23. Aboyans V, Ricco JB, Bartelink MEL, Björck M, Brodmann M, Cohnert T, Collet JP, Czerny M, De Carlo $\mathrm{M}$, Debus S, et al.; ESC Scientific Document Group (2018). 2017 ESC guidelines on the diagnosis and treatment of peripheral arterial diseases, in collaboration with the European Society for Vascular Surgery (ESVS): document covering atherosclerotic disease of extracranial carotid and vertebral, mesenteric, renal, upper and lower extremity arteriesEndorsed by: the European Stroke Organization (ESO)the task force for the diagnosis and treatment of peripheral arterial diseases of the European Society of Cardiology (ESC) and of the European Society for Vascular Surgery (ESVS). Eur Heart J, 39(9), 763816. doi: 10.1093/eurheartj/ehx095

24. Armstrong EJ, Chen DC, Singh GD, Amsterdam EA, Laird JR (2015). Angiotensin-converting enzyme inhibitor or angiotensin receptor blocker use is associated with reduced major adverse cardiovascular events among patients with critical limb ischemia. Vasc Med, 20(3), 237-244. doi: 10.1177/1358863X15574321

25. Feringa HH, van Waning VH, Bax JJ, Elhendy A, Boersma E, Schouten O, Galal W, Vidakovic RV, Tangelder MJ, Poldermans D (2006). Cardioprotective medication is associated with improved survival in patients with peripheral arterial disease. J Am Coll Cardiol, 47(6), 1182-1187. doi: 10.1016/j.jacc.2005.09.074

26. Mundi S, Massaro M, Scoditti E, Carluccio MA, van Hinsbergh VWM, Iruela-Arispe ML, De Caterina R (2018). Endothelial permeability, LDL deposition, and cardiovascular risk factors-a review. Cardiovasc Res, 114(1), 35-52. doi: 10.1093/cvr/cvx226

27. Ding N, Sang Y, Chen J, Ballew SH, Kalbaugh CA, Salameh MJ, Blaha MJ, Allison M, Heiss G, Selvin E, et al (2019). Cigarette smoking, smoking cessation, and longterm risk of 3 major atherosclerotic diseases. $\mathrm{J} \mathrm{Am} \mathrm{Coll}$ Cardiol, 74(4), 498-507. doi: 10.1016/j.jacc.2019.05.049

28. Anand SS, Bosch J, Eikelboom JW, Connolly SJ, Diaz R, Widimsky P, Aboyans V, Alings M, Kakkar AK, Keltai K, Maggioni AP, Lewis BS, Störk S, Zhu J, Lopez-Jaramillo P, O’Donnell M, Commerford PJ, Vinereanu D, Pogosova N, Ryden L, Fox KAA, Bhatt DL, Misselwitz F, Varigos JD, Vanassche T, Avezum AA, Chen E, Branch K, Leong DP, Bangdiwala SI, Hart RG, Yusuf S; COMPASS Investigators (2018). Rivaroxaban with or without aspirin in patients with stable peripheral or carotid artery disease: an international, randomised, double-blind, placebocontrolled trial. Lancet, 391(10117), 219-229. doi: 10.1016/S0140-6736(17)32409-1. Epub 2017 Nov 10. PMID: 29132880. 